\title{
Herbal use among hypertensive patients in Basra, Iraq
}

\section{Samira Muhammed Ebrahim ${ }^{1}$ and Utoor Talib Jassim² ${ }^{2}$}

$1 \mathrm{PhD}$ in Community Medicine, Department of Nursing Science, Nursing College, University of Basra, Iraq; samiraebrahim7@gmail.com

2 MSc. in Clinical Pharmacology, Department of Basic Science, NursingCollege, University of Basra, Iraq

Background:Herbal medicines, include herbs, herbal materials, herbal preparations, and finished herbal products containing active ingredients parts of plants.

The study aimedto determine the rate of herbal use,to identify the reasons for herbal use and the types of herbal use by hypertensive patients.

Methodology: the study was a descriptive one, including 200 patients with hypertension attending outpatient clinics in Basra city south of Iraq.

Results:81(40.5\%) of the participants used herbal remedies. Herbs usage was found to higher among females 42(42\%), among married 73(42.2\%), and among those who live in districts $72(63.2 \%)$.It was found to be significantly higher among those less than 54 years of age and those with institute /college level of education, and $32 \%$ of the participants used more than one herb at the same time.Garlicwas the most commonly used by $28.4 \%$. Majority $71.6 \%$ use herbal remedies on a regular bases. Friends and media were the main sources for recommendation to use herbal remedies $(29.3 \%, 23 \%)$ respectively.Being more effective and harmless was the main reason for using herbal remedies $(43.2 \%, 34.6 \%)$ respectively.

Keywords: Hypertension, patients, use, herbal remedies, Basra

\section{Introduction}

Herbalmedicines include herbs, herbal materials, herbal preparations, and finished herbal products containing active ingredients parts of plants ${ }^{(1)}$.Alternative medicine is commonly used in hypertension management ${ }^{(2)}$.The trend of using complementary alternative medicine in the control of blood pressureis growing ${ }^{(3)}$.Herbalmedicines considered as natural or traditional may lead to many peoplebelieve that these remedies are safe ${ }^{(4)}$.Recently according to the World Health Organization, $80 \%$ of people rely on herbal medicines worldwide for some part of their primary health care ${ }^{(5)}$. The creation of awareness about how safe and effective traditional medicine/complementary and alternative medicine therapies among the public is included in efforts and priorities for promoting the use of traditional medicines by the World Health Organization ${ }^{(6)}$.

In Baghdad, Iraq in 2018 a study aimed to assess hypertensivepatient'sattitudes towards complementary alternative medicine.Complementary alternative medicine was used by $65.5 \%$ of respondents and a favorable attitude towards it was related to gender and the patient's educational level ${ }^{(3)}$.

Study in Kerman,Iranto determine the rate of medicinal plants used in hypertensive patients. The results were out of 612 participants $29.4 \%$ used herbal medicine, higherfrequencyofuseofherbalmedicines among females and no significant relationship was found between marital status and length of education and the use of herbal medicines ${ }^{(7)}$.

To determine the frequency of herbal medicine use among patients with chronic diseases, the results of a studyin Ankara showed that $29 \%$ of 217 patients participated in the 
studyusedherbal medicine. And the use of herbal medicine was significantly higheramong females. The most frequently used herb by the participants was garlic ${ }^{(8)}$.

In Palestine, a study was conducted to investigate the use of herbs in the treatment of hypertension in humans. Out of 83 patients who were interviewed 59\% use herbs. The study concluded that the prevalence of herbal use among patients with hypertension in Palestine was appreciable ${ }^{(9)}$.

The result of the study conducted in Ghana showed that among 203 hypertensive patientsthe prevalence of use of herbal medicine was 66\%. And Prevalence among females was higher thanmales. The most common herbal medicine used is garlic ${ }^{(4)}$.

A study including 258 hypertensive patients in Uganda concludes that the use of alternative medicine was common among patients with hypertension and usage was underpinned by the patient's belief that alternative medicine is effective ${ }^{(2)}$.

Another study in South African showed that out of 135 traditional herbal medicine users, $21 \%$ used traditional herbal medicine to treat hypertension. The majority of $82.1 \%$ of the users were females ${ }^{(10)}$.

A recent study in Sierra Leone,aimed to measureshowed that among 260 participants, more than half $56.9 \%$ reported using herbal medicine.Garlic was the commonest used herbal medicine. And no significant difference found between users and non-users of herbal medicine with socio-demographic and health-related factors ${ }^{(11)}$.

\section{Objectives of the study}

1-Determine the rate of herbal use among hypertensive patients.

2- Identify reasons for herbal use among hypertensive patients.

3 - Identify types of herbs used by hypertensive patients.

\section{Methodology}

1-Design of the study: Descriptive, cross-sectional study.

2-Setting of the study: The outpatient clinics in Al-Basra teaching hospital and Al-zubair hospital.

3-The sample of the study: The number of samples is 200 hypertensive patients 100 patients from each hospitaldivided into 50 males and 50 females.

For data collectionstructured questionnaire was used; a collection of data was carried out from October 2018 to December 2018. The questionnaire contains two parts the first part consists of 6items related to demographic characteristics of the patients and 1 question related to hypertension, the second part consist of 11 questions related to herbal use.Data were collected by face-to-face interviewby two senior nursing students. Each interview took 5 to 7 minutes.

Approval to conduct the study was obtained before the attempt of data collectionfrom Basra general health directorate. Also, each participant (patient) was informed orally about the studyaim, they have the right refuse to participate in the study, and confidentiality of the information gathered.

4- Statistical analysis: SPSS version 23 was used for analyzing data that was presented inthe form of (frequency and percentage). To examine the association betweenthe groups.A chisquared test was used and a probability of less than 0.05 was consideredtobe statistically significant. 


\section{Results}

\section{1 -Socio - demographic characteristics of the patients.}

Out of 200 patients $81(40.5 \%)$ used herbal remedies, 108(54\%) were younger than 54years of age, $173(86.5 \%)$ were married, $101(50.5 \%)$ had secondary school level of education. Regarding the area of residence $114(57 \%)$ of patients live in district areas. Herbal remedies usage was found to higher among females $42(42 \%)$, among married patient $73(42.2 \%)$, those who live in Districts $72(63.2 \%)$ and it was found to be significantly higher among those under 54 years of age $(\mathrm{p}=0.001)$, and among those with institute /college level of education ( $\mathrm{P}$ $=0.046)$ as shown in Table 1 .

Table1. Socio-demographic characteristics and the use of herbal remedies

\begin{tabular}{|c|c|c|c|c|c|c|c|}
\hline \multirow[t]{2}{*}{ Variable } & \multirow[t]{2}{*}{ Category } & \multirow{2}{*}{$\begin{array}{l}\text { Total } \\
\text {,n }(\%)\end{array}$} & \multicolumn{2}{|c|}{$\begin{array}{c}\text { Consumers of Herbal } \\
\text { Remedies }\end{array}$} & \multirow[t]{2}{*}{$X^{2}$} & \multirow[t]{2}{*}{ Df } & \multirow[t]{2}{*}{ P-Value } \\
\hline & & & Yes, n (\%) & No, n (\%) & & & \\
\hline & $\begin{array}{l}\text { Hypertensive } \\
\text { patients }\end{array}$ & $200(100 \%)$ & $81(40.5 \%)$ & $119(49.5 \%)$ & & & \\
\hline \multirow[t]{2}{*}{ Age } & $20-54$ & $108(54 \%)$ & $55(50.9 \%)$ & $53(49.1 \%)$ & \multirow[t]{2}{*}{10.591} & \multirow[t]{2}{*}{1} & \multirow[t]{2}{*}{$0.001^{*}$} \\
\hline & $55+$ & $92(46 \%)$ & $26(28.3 \%)$ & $66(71.7 \%)$ & & & \\
\hline \multirow[t]{2}{*}{ Gender } & Male & $100(50 \%)$ & $39(39 \%)$ & $61(61 \%)$ & \multirow[t]{2}{*}{0.187} & \multirow[t]{2}{*}{1} & \multirow[t]{2}{*}{0.666} \\
\hline & Female & $100(50 \%)$ & $42(42 \%)$ & $58(58 \%)$ & & & \\
\hline \multirow[t]{2}{*}{ Marital state } & Married & $173(86.5 \%)$ & $73(42.2 \%)$ & $100(57.8 \%)$ & \multirow[t]{2}{*}{1.531} & \multirow[t]{2}{*}{1} & \multirow[t]{2}{*}{0.216} \\
\hline & Single & $27(13.5 \%)$ & $8(29.6 \%)$ & $19(70.4 \%)$ & & & \\
\hline \multirow[t]{3}{*}{ Education } & Primary school & $78(39 \%)$ & $24(30.8 \%)$ & $54(69.2 \%)$ & \multirow[t]{3}{*}{6.168} & \multirow[t]{3}{*}{2} & \multirow[t]{3}{*}{$0.046^{*}$} \\
\hline & $\begin{array}{l}\text { Secondary } \\
\text { school }\end{array}$ & $101(50.5 \%)$ & $45(44.6 \%)$ & $56(55.4 \%)$ & & & \\
\hline & $\begin{array}{l}\text { Institute } \\
\text { /college }\end{array}$ & $21(10.5 \%)$ & $12(57.1 \%)$ & $9(42.9 \%)$ & & & \\
\hline \multirow{2}{*}{$\begin{array}{l}\text { Area of } \\
\text { residence }\end{array}$} & City center & $86(43 \%)$ & $39(45.3 \%)$ & $47(54.7 \%)$ & \multirow[t]{2}{*}{1.472} & \multirow[t]{2}{*}{1} & \multirow[t]{2}{*}{0.225} \\
\hline & Districts & $114(57 \%)$ & $72(63.2 \%)$ & $42(36.8 \%)$ & & & \\
\hline
\end{tabular}

$* \mathrm{P}<0.05$ considered as statistically significant

\section{2 - Types of herbal remedies}

As reported by the participants, $32 \%$ usemore than one herb at the same time.Garlic was the most commonly used $28.4 \%$, Basil use was reported by $9.8 \%$, Cumin $7.4 \%$, as shown in Table 2.

Table 2. Herbal remedies used according to the patients $(n=81)$

\begin{tabular}{|l|l|l|l|}
\hline Items & Traditionallocal name & No. & $\%$ \\
\hline Garlic & Thom & 23 & 28.4 \\
\hline Basil & Ryhan & 8 & 9.8 \\
\hline Cumin & Kamon & 6 & 7.4 \\
\hline Cardamom & Heil & 5 & 6.2 \\
\hline Ginger & Zengabel & 5 & 6.2 \\
\hline Cinnamon & Darcein & 4 & 5 \\
\hline Fenugreek & Helba & 2 & 2.5 \\
\hline Celery & Krufes & 2 & 2.5 \\
\hline More than one type & & 26 & 32 \\
\hline
\end{tabular}




\section{Attitude and pattern of use of herbal remedies}

Majority $71.6 \%$ use herbal remedies on a regular bases. The ultimatedecision to use herbs is a personal decision, Friends and media were the main sources for recommendation to use herbal remedies $(29.6 \%, 21 \%)$ respectively. Being more effective and harmless was the main reason for using herbal remedies $(43.2 \%, 34.6 \%)$ respectively. Regarding informing the doctor about the use of herbal remedies only $(40.7 \%)$ of the patients did so, and the majority of them were encouraged by the doctors (93.9\%). The main reason for not informing the doctor was that patients think it is not important to tell the doctor as reported by $54.2 \%$ as shown in Table 3.

Table 3: Attitude and pattern of use of herbal remedies $(n=81)$

\begin{tabular}{|l|l|l|l|}
\hline Item & Categories & No. & $\%$ \\
\hline Pattern of use herbal remedies & Regular & 58 & $\mathbf{7 1 . 6}$ \\
\cline { 2 - 4 } & Irregular & 23 & 28.4 \\
\hline $\begin{array}{l}\text { Sources of recommendation } \\
\text { for the use of herbal remedies }\end{array}$ & Self-influenced & 9 & 11.1 \\
\cline { 2 - 4 } & Family & 16 & 19.8 \\
\cline { 2 - 4 } & Friends & 24 & $\mathbf{2 9 . 6}$ \\
\cline { 2 - 4 } & Health care personnel & 10 & 12.3 \\
\cline { 2 - 4 } & Herbalist & 5 & 6.2 \\
\cline { 2 - 4 } & Media & 17 & $\mathbf{2 1}$ \\
\hline Reasons for using herbal & Available & 16 & 19.8 \\
\cline { 2 - 4 } remedies & Cheap & 2 & 2.5 \\
\cline { 2 - 4 } & More effective & 35 & $\mathbf{4 3 . 2}$ \\
\cline { 2 - 4 } & Harmless & 28 & $\mathbf{3 4 . 6}$ \\
\hline Did you Inform your Doctor? & No & 48 & 59.3 \\
\cline { 2 - 4 } & Yes & 33 & $\mathbf{4 0 . 7}$ \\
\hline $\begin{array}{l}\text { What is the Response of the } \\
\text { doctor when you inform him }\end{array}$ & Encourage you & 31 & 93.9 \\
\cline { 2 - 4 } & Discourage you & 2 & 6.1 \\
\hline $\begin{array}{l}\text { Reason for not informing } \\
\text { your doctor }\end{array}$ & $\begin{array}{l}\text { Didn't know doctor should } \\
\text { be informed }\end{array}$ & 12 & 25 \\
\cline { 2 - 4 } & Afraid of doctor response & 10 & 20.8 \\
\cline { 2 - 4 } & $\begin{array}{l}\text { I think it is not important } \\
\text { to tell the doctor }\end{array}$ & 26 & 54.2 \\
\hline \multirow{4}{*}{} & & & \\
\hline
\end{tabular}

\section{Discussion:}

This is the first study in Basra that identified the rate of herbal remedies use was as common as (40.5\%) among hypertensive patients. The rate observed in our study falls within the range from $24.4 \%$ to $67.8 \%$ which was reported inPrevious studies in Iraq and other countries ${ }^{(1,7}$, $8,9,10,12,13,14,15)$.

The reported differences in herbal rates used might be due to differences in sociodemographic features of the study population even in the same country. 
In ourstudy, it was found that as patients get older the rate of the use of herbal remediesdeclines, a similar pattern in other studies ${ }^{(13,14,16)}$. This might be dueto that older patient's dailyactivity will be limited so they become more dependent on their surroundings to purchase theseproducts, alsobecome more dependent on health care facilities and intake of conventional drugs.

Although in our study, there were no statistically significant differences between the rate of herbal remedies use and gender, marital status, or place of residence (district) among the hypertensive subjects.Herbal remedies tend to be used byfemales more than males. This finding was compatible with otherstudies ${ }^{(7,8,9,10,17)}$,this could be due tothatlarge proportion of women in our community are housewives and they spend more time watching television and other media especially programs directed toward women, herbal medicines are mentioned a lot on these kinds of programsand women found to pay greater attention to their health.Also being the traditional caretakers of the family's health and their knowledge on medicinal plants exceeds those of men as mentioned by many studies ${ }^{(8,14,16)}$.Also, this study showed that the rateof herbal use was higher among married than among unmarried patients this could be to the influence of females regarding this aspect.Patients who were living in districts use herbs more than those in the city center similar pattern was found in other studies $(2,8,9)$.

In contrast to the studies ${ }^{(3,4,7,9,15,17)}$, this study found that people with high education levels were more likely to use herbal medicines. This may be due that educated people have more access to literature and media and try to search more about what is new in the management of their disease.

Herbs used in our study were relatively safe plants and are commonly used daily as food or beverage. The most common herb usedwasgarlic $28.4 \%$ which didn't differ much than the study done in Baghdad $(31.0 \%){ }^{(12)}$, but higher than the studies done in Turkey $(15 \%)^{(17)}$, $\operatorname{Jordan}(16 \%)^{(18)}$.

Our study showed that the majority of the patients use herbs on regular bases, this could be due to the benefits that patients found after the usage of herbal remedies in the management of hypertension.

Friends as Sources of recommendation for the use of herbs as mentioned by $29.6 \%$ of the sample, lower than what was found for studies done in Iraq and other countries ${ }^{(12,14,19,20)}$.

The main reason for using herbal remedies as reported by those patients it is to be more effective, other study mentioned that using herbal remedies most users believed that herbal remedies were either equally or more efficacious than conventional medicines ${ }^{(4)}$.

In our study, 59.3\% of patients did not inform theirdoctor about their herbal remedies use. This rate was lower than the study done in the university of Ghana $91.0 \%{ }^{(4)}$, Sierra Leone $(85.1 \%)$ (21), Palestine $(79.5 \%)^{(7)}$. The reason for not informing the doctorabout using herbal remedies $54.2 \%$ of patients say I think it is not important to tell the doctorand thiswas higher than the study done in the university of Ghana $18.4 \%{ }^{(4)}$.

In Iraq, the availability and relatively low cost of herbs in the markets with cultural acceptability and the traditional use of herbs for several healthconditionsincrease patient's confidence to usethem in the management of hypertension.

Conclusions

The use of herbal remediesfound to be a common practice among hypertensive patients in Basra city.It was found to be higher among females, married, and those who live in districts and significantly higher among those with institute /college level of education.Garlic was the main type of herbs that have beenused.And the main source of recommendation for the use of herbal remedies was friends. The main reason for using herbal remedies was the belief in being more effective. 


\section{Recommendations}

1-Health care providers should make a comprehensive assessment to identify complementary therapies used by their patients.

2-Herbal medicine information regarding their effect on blood pressure should be provided to the hypertensive patients this can be done through media, journals and health talks at health facilities.

\section{Conflict of Interest: Nil \\ Source of Funding: Self-funding}

\section{References}

1. Liwa A, Roediger R, Jaka H, Bougaila A, Smart L, Langwick S, Peck R. Herbal and alternative medicine use in Tanzanian adults admitted with hypertension-related diseases: A Mixed -Methods Study. International Journal of Hypertension 2017;(3):1-9.

2. NuwahaF, Musinguzi G. Use of alternative medicine for hypertension in Buikwe and Mukono districts of Uganda: a cross-sectional study. Complementary and Alternative Medicine 2013;13:301-6.

3. Ibrahim I R, Hassali M.A, Saleem F, AlTukmagi HF, Dawood OT. Patients Attitudes towards Complementary and Alternative Medicine: A cross-sectional study among Hypertensive patients in Baghdad,Iraq. Journal of Complementary medicine and alternative healthcare 2018; 7 (3):1-8.

4. Asante A A. Use of herbal medicine among hypertensive patients Ghana east district, greater Accra. Master thesis; School of public health, collegeof health sciences, University of Ghana 2012.

5. Alkhazrajy L A, Habib H A, Alsudani Z I. Perception of Iraqi primary health care providers about herbs in practice. European journal of botany, plant science, and phytology. 2014; 1(1): 27-52.

6. Abahussain N A, Abahussain E A, Al-oumi F M. Pharmacists attitudes and awareness towards the use and safety of herbs in Kuwait.Pharmacy Practice(Granada) 2007;5(3).

7. Tajadini H, Divsalar K, Mehrabani M, Haghdoost A A, Esmaili Z, Shadkam M,Moradi M. The frequency of using herbal medicines among patients with hypertension in Karman,Iran. Journal of evidence-Based Complementary and Alternative Medicine 2015;20(3) 199-202.

8. Tulunay M, Aypak C, Yikilkan H, Gorpelioglu S. Herbal medicine use among patients with chronic diseases. Journal of intercultural ethnopharmacology. 2015;4(3):217-220.

9. Humidat A S,Khamaysa L S. The use of herbal medicines by people with hypertension in Palestine. International journal of technology enhancements and emerging engineering research.2013;2(7):131-134.

10. Hughes GD, Aboyade O M,Clark B L, Puoane T R. The prevalence of traditional herbal medicine use among hypertensive living in South African communities.The official journal of the international society for complementary medicine research(ISCMR) 2013;13:38.

11. James P B, Kamara H, Bah A J, Steel A, Wardle J. Herbal medicine use among hypertensive patients attending public and private health facilities in Freetown Sierra Leone. Complementary Therapies in Clinical Practice 2018;31:7-15

12. Ibrahim I R, Hassali M A, Saleem F, ALtukmagi H F, Dawood O T. use of complementary and alternative medicines: a cross-sectional study among hypertensive patients in Iraq. Journal of Pharmaceutical Health Services Research 2018;9:59-65. 
13. Bright Adjei B A (Hons).Utilization of traditional herbal medicine and its role in health care delivery in Ghana: Thecase of Wasa Amenfi West district.Masterthesis; College of Art and Social Sciences 2013.

14. Hajbaghery M A, Rafiee S. Medical plants use by elderly people in Kashan, Iran .nursing and midwifery studies 2018;7(2):67-73.

15. Mushabab Ayed Alghamdi, Abdel Gaffar A. Mohammed1, Fahad Alfahaid2, Ali Albshabshe3.Herbal Medicine Use by Saudi Patients with Chronic Diseases: A Crosssectional Study (Experience from Southern Region of Saudi Arabia). 'Journal of Health Specialties ? Volume 6 ;ssue 2 ; April-June 2018:77-81

16. Ngcobo Z N.The use of indigenous medicine for the treatment of hypertension by a rural community in northern Maputaland,South Africa. South African Journal of Botany 2016;103:78-88.

17. Bahar Z, Kızılcı S, Beşer A, Besen DB, Gördes N, Ersin F, Kissal A, Çapık C. Herbal Therapies Used by Hypertensive Patients in Turkey. Afr J Tradit Complement Altern Med. 2013; 10(2): 292-298.

18. Issa R A, Basheti I A.Herbal products use among chronic patients and its impact on treatment safety and Efficacy: Aclinical survey in the Jordanian Filed. Trends in medical research 2017;12(1):32-44.

19. Cotterell K, Fray R, Clarke O, Daley K. Knowledge and attitudes of patients living with hypertension toward herbal medicine versus conventional drug therapy in Kingston and St.Andrew, Jamaica.University of Technology, Jamaica 2016;1-43.

20. Elolemy A T, Radwan N M, Dawood W, Ali I, Fouda L M. Complementary and alternative medicine use among health workers in Mid -Delta, Egypt. Majmaah Journal Health sciences 2013;1(2):35-42.

21. James P B, Kamara H, Bah A J, Steel A, Wardle J. Herbal medicine use among hypertensive patients attending public and private health facilities in Freetown Sierra Leone. Complementary therapies in clinical practice 2018;31:7-15 